\title{
BPM Development for Insurance Claims Using Pega
}

\author{
Nikhil Chaudhari ${ }^{1}$, Astitv Nagpal ${ }^{2}$ and Santhi H. ${ }^{3}$ \\ ${ }^{1,2,3}$ VIT University, Vellore, India \\ Inikhil.chaudhari2013@vit.ac.in, ${ }^{2}$ astitv96@gmail.com, ${ }^{3}$ hsanthi@vit.ac.in
}

\begin{abstract}
USA's insurance industry premium in 2015 was totalled to be 1.2 trillion USD and there were about six thousand insurance companies. To manage all the information and keep up with the ever-changing rules and regulations of government about the insurance policies demands a fast and robust application. This paper aims to explain such an application. Pega is used to build this application because of Pega's benefits such as Direct Capture of Objectives (DCO), Situation Layer Cake, etc are used by most of the leading businesses nowadays. The paper also discusses some of the other software used in BPM development like Oracle and IBM. An application system is created using Pega PRPC which can handle multiple insurance claims. The system has different lines for handling different claims like health, auto, home, travel, etc. Pega's unique features are used not only to create the application but also allow system architects to maintain the system.
\end{abstract}

Keywords: Insurance claims, Pega PRPC, Indian insurance sector, Online insurance

\section{Introduction}

The coming year will assume a significant position in the history of Indian insurance industry. It denotes completion of a decade of open-market; ending of oligopoly and entry of private sector insurance companies; and the regime of a new development oriented regulatory authority - the IRDA (Insurance Regulatory and Development Authority). Virtusa has developed an application which works in USA and South America. This paper aims to describe a similar software biding to Indian rules, regulations and policies.

Currently, the general insurance market has more than 20 players already and some more large international ones are expected to enter shortly. Companies today are coming up with new ideas to stand out and they are offering the existing and prospective customers with new technology platforms that would streamline the business and would also be beneficial to them. The recent development in the general insurance sector is the activities by the insurance regulator. The IRDA has been very stringent and has been keeping a close-watch on the functioning of all the insurance companies. The latest regulation from IRDA is on health insurance portability. In the future, general insurance industry will be very much in the limelight than any other industry facing recession now.

Online selling of insurance policies to discerning customers, who access the Internet will gain momentum. Typically motor, travel and health policies will be sold more online. Many insurers have already realised this and are creating separate verticals to exploit this segment. The interplay of technology \& telecom solutions will be a major factor determining the growth of the industry in the future. Similarly, as the selling of insurance policies gain momentum and this domain's customers grow more and more comfortable with the digital world, online claim filing will also be in demand.

The Indian customers are demanding and expect best in class service levels so the entire insurance industry will have to work towards becoming more customer-centric in the areas of product development, policy issuance as well as claims settlement. They would need to constantly do market research to update their products, services \& 
processes to keep up with the changing needs of their customers. India's insurable population is expected to touch 750 million in 2020. Managing all the information and keep up with the ever-changing rules and policies of government demands a fast and robust application. The authors of this paper develop such an application which focusses on Indian insurance market. The application is developed using Pega PRPC.

\section{Motivation}

The country's insurance market is expected to quadruple in size over the next 10 years from its current size of US\$ 60 billion. During this period, the life insurance market is slated to cross US $\$ 160$ billion. The general insurance business in India is currently at Rs 78,000 crore (US\$ 11.44 billion) premium per annum industry and is growing at a healthy rate of 17 per cent. The Indian insurance market is a huge business opportunity waiting to be harnessed. India currently accounts for less than 1.5 per cent of the world's total insurance premiums and about 2 per cent of the world's life insurance premiums despite being the second most populous nation. The country is the fifteenth largest insurance market in the world in terms of premium volume, and has the potential to grow exponentially in the coming years.

Government Initiatives:

The Union Budget of 2017-18 has made the following provisions for the Insurance Sector:

- The Budget has made provisions for paying huge subsidies in the premiums of Pradhan Mantri Fasal Bima Yojana (PMFBY) and the number of beneficiaries will increase to 50 per cent in the next two years from the present level of 20 per cent. As part of PMFBY, Rs 9,000 crore (US\$ 1.35 billion) has been allocated for crop insurance in 2017-18.

- By providing tax relief to citizens earning up to Rs 5 lakh (US\$ 7500), the government will be able to increase the number of taxpayers. Life insurers will be able to sell them insurance products, to further reduce their tax burden in future. As many of these people were understating their incomes, they were not able to get adequate insurance cover.

- Demand for insurance products may rise as people's preference shifts from formal investment products post demonetization.

- The Budget has attempted to hasten the implementation of the Digital India initiative. As people in rural areas become more tech savvy, they will use digital channels of insurers to buy policies and file claim online.

- The Union Cabinet has approved the public listing of five Government-owned general insurance companies and reducing the Government's stake to 75 per cent from 100 per cent, which is expected to bring higher levels of transparency and accountability, and enable the companies to raise resources from the capital market to meet their fund requirements.

- IRDAI has formed two committees to explore and suggest ways to promote ecommerce in the sector to increase insurance penetration and bring financial inclusion.

- The Government of Assam has launched the Atal-Amrit Abhiyan health insurance scheme, which would offer comprehensive coverage for six disease groups to below-poverty line (BPL) and above-poverty line (APL) families, with annual income below Rs 500,000 (US\$ 7,500).

- The Uttar Pradesh government has launched a first of its kind banking and insurance services helpline for farmers where individuals can lodge their complaints on a toll free number.

- The select committee of the Rajya Sabha gave its approval to increase stake of foreign investors to 49 per cent equity investment in insurance companies. 
- Government of India has launched an insurance pool to the tune of Rs 1,500 crore (US\$ 220.08 million) which is mandatory under the Civil Liability for Nuclear Damage Act (CLND) in a bid to offset financial burden of foreign nuclear suppliers.

- Foreign Investment Promotion Board (FIPB) has cleared 15 Foreign Direct Investment (FDI) proposals including large investments in the insurance sector by Nippon Life Insurance, AIA International, Sun Life and Aviva Life leading to a cumulative investment of Rs 7,262 crore (US\$ 1.09 billion).

- IRDAI has given initial approval to open branches in India to Switzerland-based Swiss Re, French-based Scor SE, and two Germany-based reinsurers namely, Hannover Re and Munich Re.

The future looks promising for the insurance industry with several changes in regulatory framework which will lead to further change in the way the industry conducts its business and engages with its customers. To handle the number of projected claims which will come with these many number of insurance policies, an application was required which can work seamlessly and smoothly from any device for claim filing. As the insurance policies are given both state government and central government, the proposed application will use the SLC (Situation Layer Cake) to use the same application for national rules as well as the state policies. Hence need of a new claim processing application arose.

\section{Literature Survey}

\subsection{Survey of the Existing Model/Work}

BPM can be described as "process optimization process". BPM aims to improve corporate performance by managing company's business processes. In the traditional style of development, the business analyst works with executive stakeholders to identify objectives and document a requirements document. This document is forwarded to information technology (IT) department where a system architect (SA) produces functional specifications which are converted to design specifications and entity relationship (ER) diagrams. These documents are disseminated to respective teams for development. The database administrator and database developers work on the database of system, UI designer works on wireframes which are passed on to HTML developers to develop front end. While another team works on integrations of these modules. And these modules are merged to form a complete system which is tested using sample data. This may still have some differences from original specifications. The change process is equally long, time-consuming and requires a lot of coordination and understanding. 


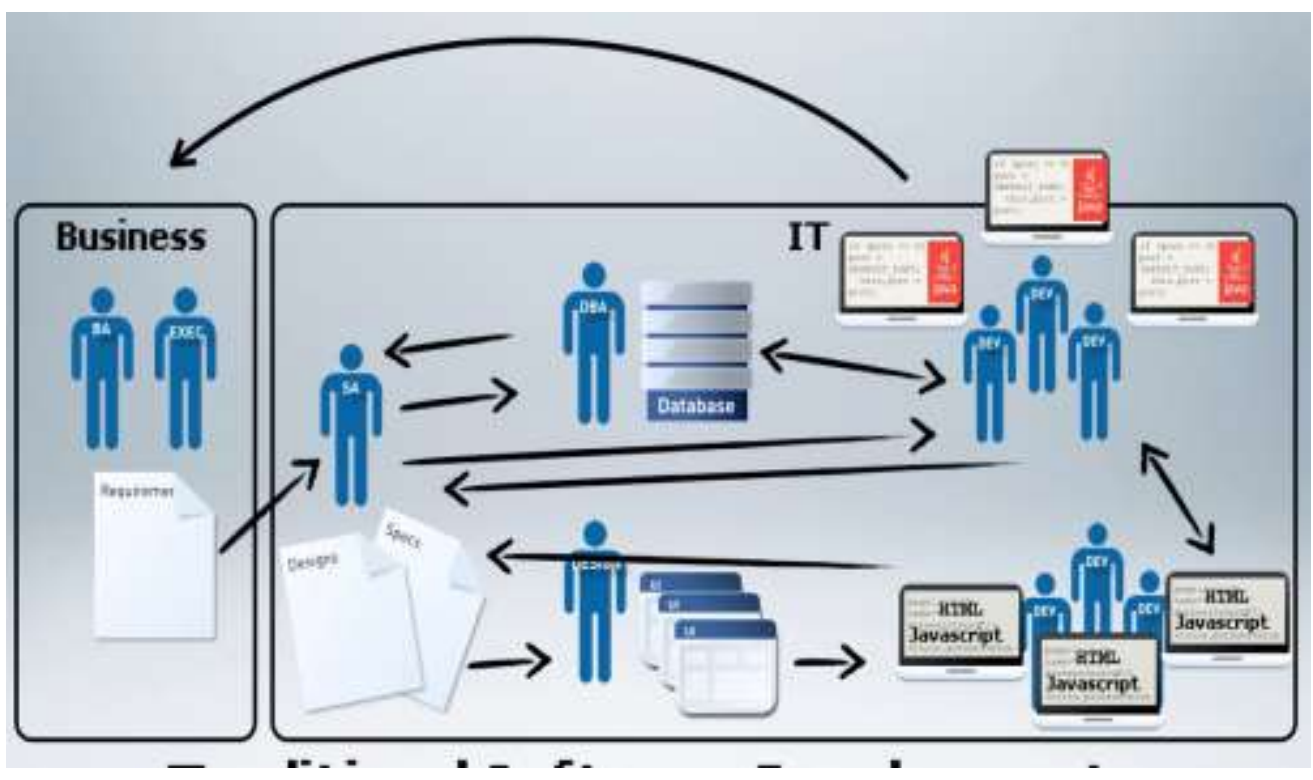

Figure 1. Traditional Style of Developing Business Applications

Compared to this process Pega PRPC allows everything to be done at one place. The business analyst works with executive stakeholders and system architects to create a visual model of the work process. The PRPC automatically generates the code to implement the process and the process can be modified easily through the designer studio. Pega is built to put the customer at the centre. The Customer Oriented Architecture brings data, intent, and process. This allows companies to get a 1080-degree view. This is why, many of world's best brands and organizations chose Pega to enhance drive growth, revenue efficiency. In a Nutshell, a slight miscommunication can lead to a large change as the change is passed down to the lower level developers. Moreover, custom built applications require constant inputs from the client. A BPM-based development approach applies techniques and development tools for creating process applications that permit continuous, iterative improvement of all the processes involved in running a business. Custom applications are exploding because of one simple fact: the entire world today runs on software and applications. We run software everywhere - on local machines, in massive data centres, in the cloud, and on personal devices. Custom applications are helping to fill this market need - but at a cost. Each of those applications costs a ton of money, not only to build but also to update and support each year. In 2014 alone, the cost of supporting and maintaining an application increased by twenty nine percent. There's no end in sight to these maintenance cost hikes, either. Beyond cost, is how the hard-coded nature of the applications makes them resistant to change. If you need customization but don't want to go to the custom development route, then there are other application development platforms out there that can be used to turn out applications quickly, but their customization capability is generally limited.

The custom BPM application require several revisions before actual roll out can begin. But using traditional techniques for such application will take a lot of time and ask a lot of patience from the lower level developers. Contrary to this Pega takes much less personnel and time for application development. The following section describes the application development in different tools.

\subsection{BPM Application Development using Tools and Software other than PEGA}

- Using Oracle

Typical workflow for creating projects, model processes, blueprints, business rules are listed below to compare the tediousness of development using Oracle versus Pega. 
Typical Workflow for Using Oracle BPM Studio to Create Project Templates

a) Determine the business requirements (process analyst).

b) Model the required business processes using Oracle BPM Studio (process analyst or process developer) A process analyst can use the Process Analyst role in Oracle JDeveloper.

c) Implement the processes by integrating each element of the process with back-end systems and reusable services (process developer).

d) Create a project template using Oracle BPM Studio (process developer)

e) Publish the project template to the Oracle BPM MDS repository (process developer)

f) Create a new Oracle BPM project based on a project template (process analyst).

g) Implement the required reusable services defined by the project template (process analyst).

h) Deploy the project to Oracle BPM run time (process analyst).

Typical Workflow for Using Oracle BPM Studio to Model Processes

a) Determine the business requirements (process analyst).

b) Model the required business processes using Oracle BPM Studio (process analyst or process developer) A process analyst can use the Process Analyst role in Oracle JDeveloper.

c) Run a simulation to test and improve process performance. (process analyst / process developer).

d) Implement the processes by integrating each element of the process with back-end systems and reusable services (process developer).

e) Compile the Oracle BPM project as a composite application (process developer).

f) Deploy the application to the run-time environment (process developer, business administrator).

g) Interact with the deployed processes as part of a running business application (process participants, process owner).

h) Maintain and monitor the running process-based applications (business administrator, process owner).

Typical Workflow for Using Business Process Composer to Create Process Blueprints

a) Create process blueprints using Business Process Composer (process analyst).

b) Provide implementation details for the business process and prepare the processbased business application for deployment (process developer).

c) Create project templates and publish them to the Oracle BPM Metadata Store repository using Oracle Business Process Management Studio (process developer).

d) Create a project based on the project template (process analyst).

e) Edit the project as defined by the edit policies of the project template (process analyst).

f) Deploy the project to Oracle BPM Run Time (process analyst, process administrator).

Typical Workflow for Using Process Composer to Revise Oracle Business Rules

a) Model a set of business processes (process analyst).

b) Implement and deploy an application (process developer).

c) Edit the Oracle Business Rules at run time using Business Process Composer. (process owner).

Typical Workflow for Using the Oracle Business Process Analysis Suite and Oracle BPM Suite to Model Processes

a) Determine the business requirements (process analyst).

b) Design your business architecture by capturing strategic objectives, process maps, value chain diagrams using Oracle Business Process Analysis (process analyst).

c) Perform strategic analysis to determine potential process candidates for Oracle BPM projects. (process analysts) 
d) Design detailed process flows for the process candidates identified previously (process analyst)

e) Import your process models into Oracle BPM Studio (process analyst, process developer).

f) Implement the processes by integrating each process component with back-end systems and reusable services (process developer).

g) Deploy the business processes, as a BPM project, to the run time environment (process developer, business administrator).

h) Interact with the deployed processes as part of a business application (process participant, process owner)

i) Maintain the processes (business administrator, process owner)

- Using IBM

Similar to Oracle, a typical BPM scenario's road map is listed below using IBM development tool.

\section{Assessment phase}

a. High level design

b. Project scope and plan

\section{1st Iteration}

a. Application framework development

b. Initial object model defined

c. Initial rule set defined

d. Process flow created

e. Basic deployment to development environment

f. Initial governance plan created

2nd Iteration

a. Live database connection established

b. Framework refined

c. New rules added

d. Add user interface

e. Process flow updated

3rd Iteration

a. Integration points refined

b. Object model refined

c. Additional rules added

d. Refine user interface

e. Process flow added

f. User training

Using Pega, the system architect designs a case, the he creates the case diagram as the client requests. The case diagram has several processes and these steps has actions which specifically describes a task. The system architect can control the flow and other required features from this case diagram. This is basically completes the flow and can be shown in a figure to client for checking. If client is satisfied then the system architect can move on to develop the sections which are a part of UI. Again, these sections can be shown for client's feedback. And then the system architect can move to properties, which are the variables. This is almost all for development. Comparing to other tools this is a lot small and also client gets to see the process flows and live interfaces.

\subsection{Gaps identified in the survey}

i. Every country has specific rules and regulations for applying for an insurance which any insurance company must follow.

ii. After country specific, there are region specific rules and regulations which have to be followed by the insurance company.

iii. After region specific, we have area specific rules and regulations. 
iv. The conventional systems cannot incorporate these different rules in a single application.

v. The companies used to develop different applications for different countries and then they used do it manually on paper for the region specific and area specific insurance companies.

vi. They used to have more of paper work which used to be very slow when giving the final statement for the insurance amount.

vii. There should to be a single manager handling a single user which in turn used to slow down the process in case the manager is on leave.

viii. Furthermore, since the process was not automated there was some politics played as well in the system which used to cost a huge loss for the user.

ix. There was no data security as the data entered was written on papers and no secure methods were considered.

$\mathrm{x}$. There was no backup kept in case there was a shortage of employees for a particular user and there was endless waiting in the process.

xi. There were many hidden rules and conditions which the user was unable to know because of the paper work and everything.

xii. No digitization and hence the process was not very efficient.

\section{System Model with Description of the Software}

The whole system will consist of many modules. Each module represents a different insurance line. Each of the lines will modules for claims intake, adjunction, and management. The modules may include lines like auto physical damage, injury claim, home-owner, health, life and commercial. The system will have automated decisionmaking capabilities and user-friendly design, which is unambiguous and intuitive. The model may also have integrated working.

The BPM life cycle typically includes design, model, execute, monitor and optimize. PRPC roughly combines the first three steps into one and increases development speed, which allows businesses to focus more on optimization and customer interaction. Pega PRPC (Pega Rules Process Commander) is a platform to automate work and automate programming. Instead of individually coding the modules separately by different development teams or individuals, PRPC provides one environment to develop all the modules and even test them.

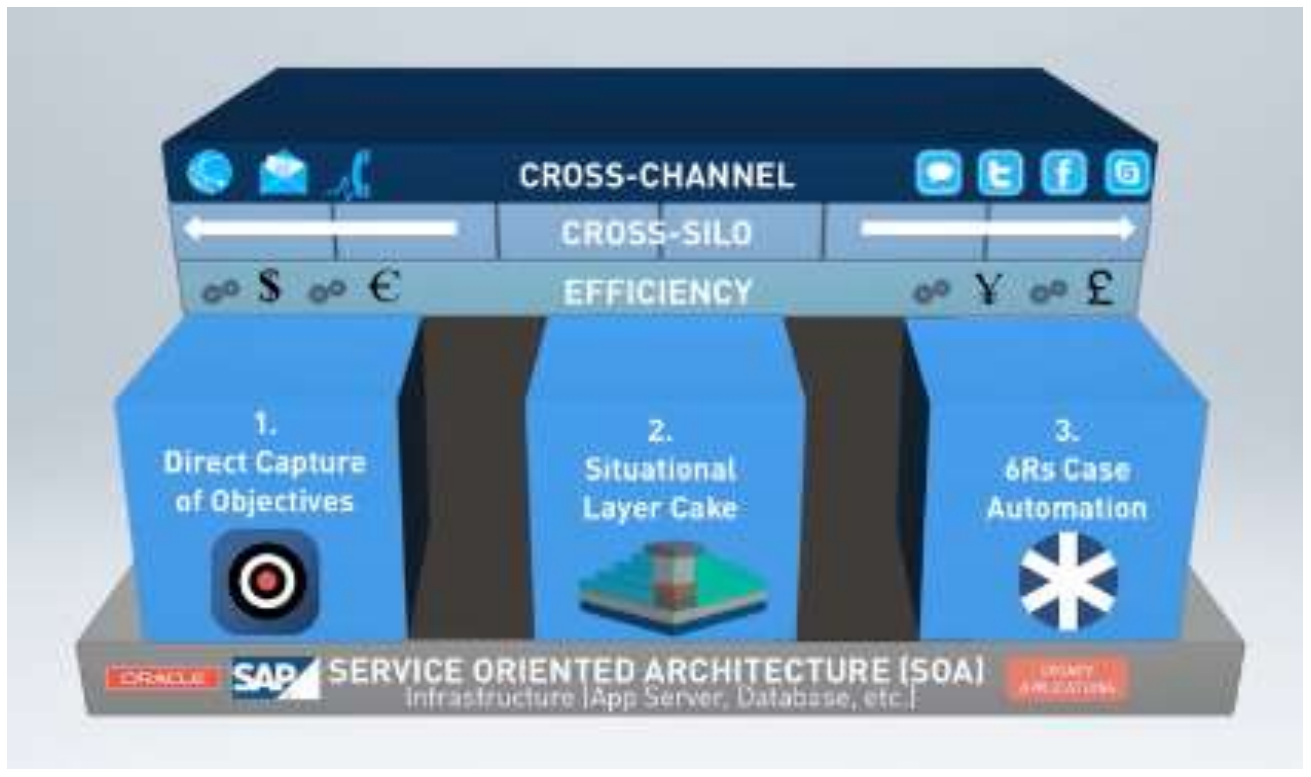

Figure 2. Three Components of Pega 
The heart of Pega is three components, namely, Direct Capture of Objectives (DCO), Situational Layer Cake (SLC) and 6R Case Automation. These core components fill in the gaps created in execution by the legacy systems and cross platform implementation.

The Pega PRPC provides the following:

1. Unified platform

2. Model Driven approach

3. Business and IT work together decreasing the time taken to develop

4. Uses editors and forms only for development

5. Absolutely no coding

Adding to the aforementioned capabilities Pega is built for change. As opposed to traditional approach where change starts from updating functional specifications, then redesigning the UI, updating the databases, changing the code and then integration testing, PRPC automatically updates the code for the modified models. Reports for monitoring and analysis are also very important part of every business. PRPC creates dozens of out of the box reports which allows business analysts to create customs reports.

The following diagrams display the process flow of home insurance and auto insurance. The user need to move to claim section from the main screen for claim filing in the dashboard provided to him. The next screen asks for claim details. The details are sent for verification. In the case of auto, the manager may ask the garage owner about the loss estimate and the police station officer about the FIR. Also, the manager may ask the passenger about the incident. In case of home insurance, the manager may ask the police in case of burglary. After the verification step, the claim amount is decided. The system was developed with an automated claim estimate calculator. The estimate was calculated using the amount of damage. For example, in case of auto insurance, the damage was rated by the client. This damage was verified and if the verification was found to be correct, the damage rating was used to calculate an amount using a multiplier. This amount is still changeable by the manager on the next screen where he gives the final quotation. This quotation is displayed to the client and if accepted then the final quotation is displayed with declaration from the user. 

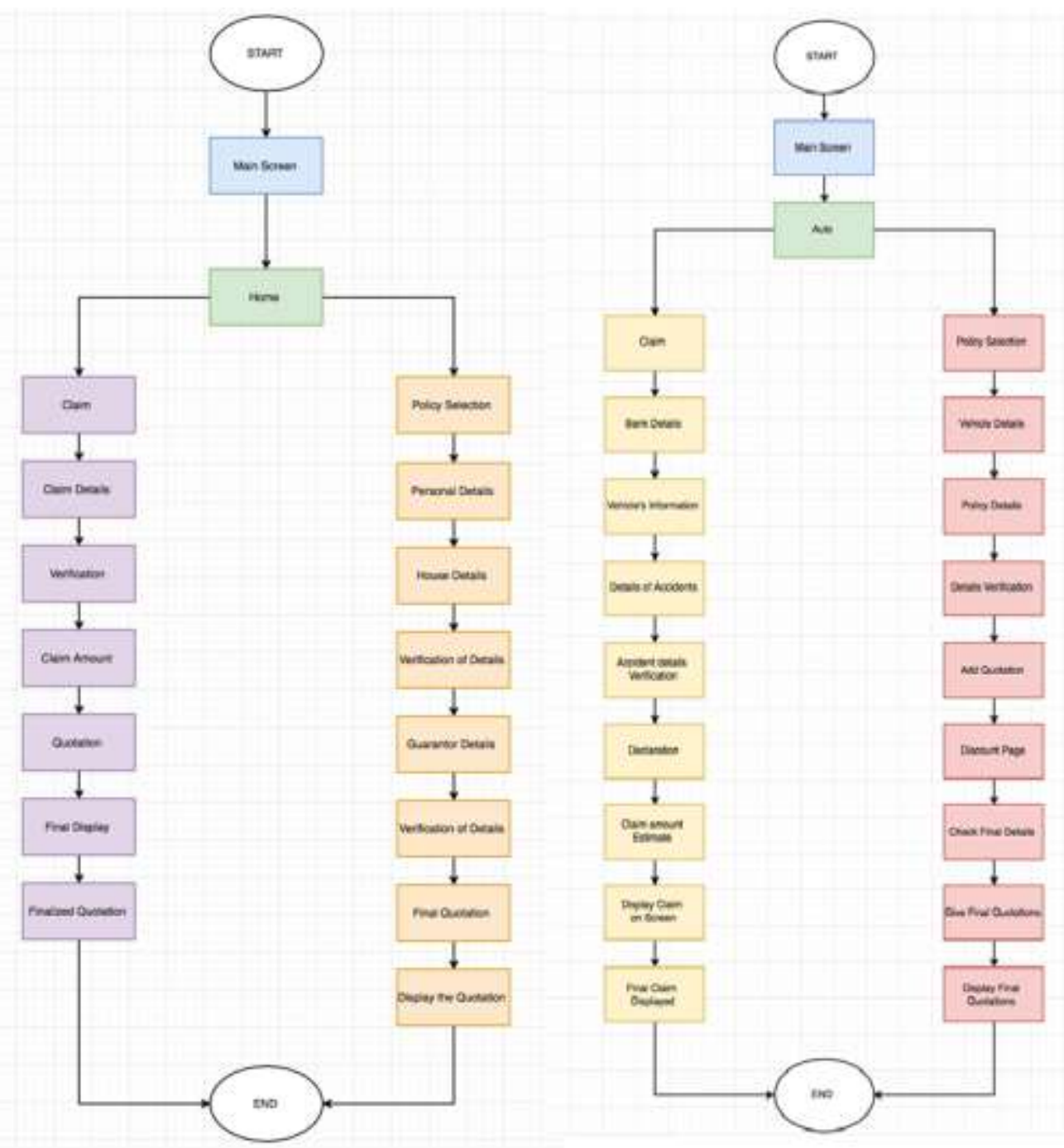

Figure 3. Process Flows of Home and Auto Insurance

Using Pega, we can design the Business Process Flow and decide the functionality we need to the Flow. Pega does the rest and deploy them as web services, develop UI using the built-in framework and deploy them in the intranet or cloud, implement CRM solutions for sales, marketing, operations and customer service. The process flow diagrams of auto insurance and house insurance include the policy selection stream for an added capability of insurance policy selection.

\section{Snapshots of the Developed Application}

The following section includes figures of screenshots which were captured while running an instance of Auto claims flow. This is similar to all other claims. The client first need to login using his assigned credentials which a part of access group "User@BOFAccApp". This access group is specifically created for clients. The screenshots are separated by a black horizontal line for better viewing. 


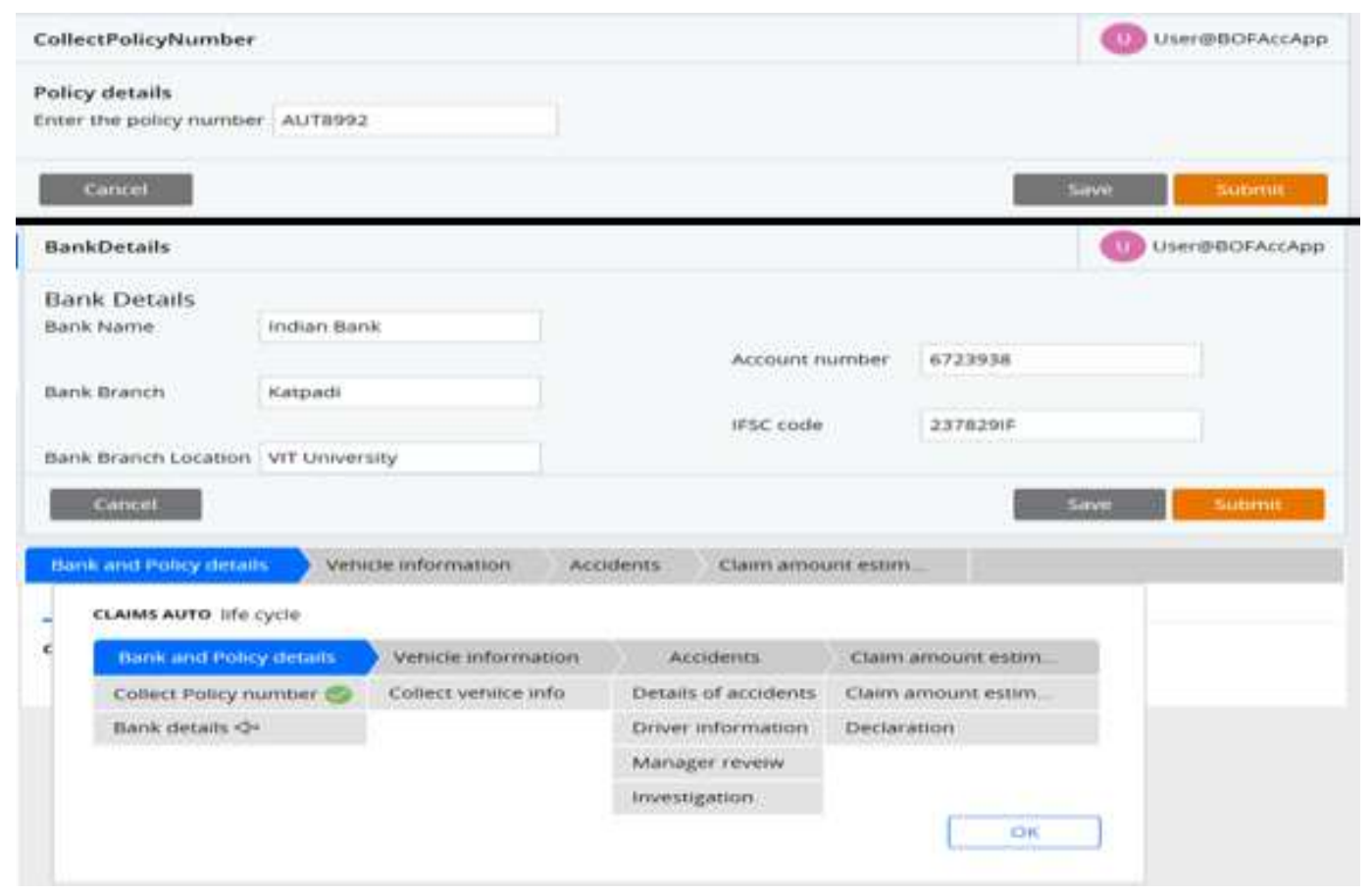

Figure 4. First Two Screen of the Auto Claim

On selecting the claim filing for auto policy, the client lands on the Collect Policy number screen. This screen asks for policy number which is shown in Figure 4. The client is supposed to enter the policy number which he got while buying the insurance policy. After entering the policy number, submit button needs to be clicked. This action leads to next screen which asks for bank details. As the name suggests the screen is responsible for collecting bank details of the client. The lower screenshot also has life cycle drop down, which can be accessed by clicking on the strip just below the user working area. This dropdown section shows all the steps. The steps completed shown by a green arrow. The current step is marked by a blue arrow. And the further steps are unmarked. In this screenshot, we can clearly see that, "Collect Policy number" step has been marked with green arrow, which we completed just before this step. And now the blue arrow is indicating towards the "Bank details" step. Also, we can see that next steps are "Collect Vehicle information", "Details of accident", etc. This allows the client to know which steps are finished and which steps are followed.

The next process is Vehicle information, which is documented in first screenshot of Figure 5. The details like vehicle registration number, engine number and chassis number is asked for verification by the officials. The second screenshot asks the details of the accident in details. One of the field, asks client about the estimated loss to get an idea of cost which client thinks. Also, in the same section, the client is asked to rate the damage to his vehicle. These ratings are used to calculate the estimated claim amount, which is shown in the manager screen. The ratings are multiplied with a factor depending on the importance of the part and final value is calculated after adding all the values. The data like name of police station and name of garage is also collected for verification. The third screenshot in the Figure 5 shows requests for driver information. This also is used for verification. The manager may call the driver to check the integrity of described incident mentioned in the claim. On clicking the submit button at this stage, will send the claim application to manager work pool. 


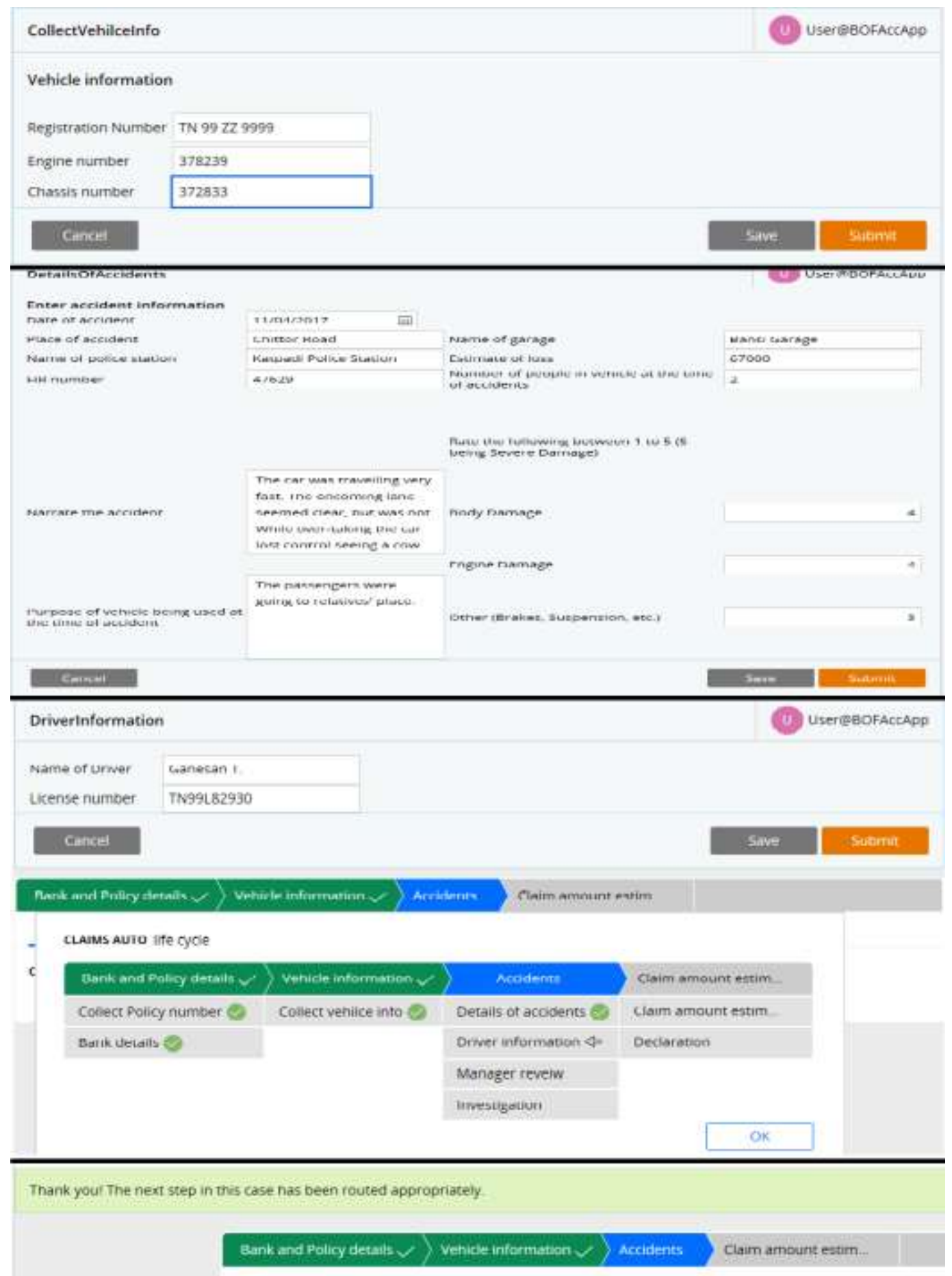

Figure 5. Screens Asking About the Details of Accident 


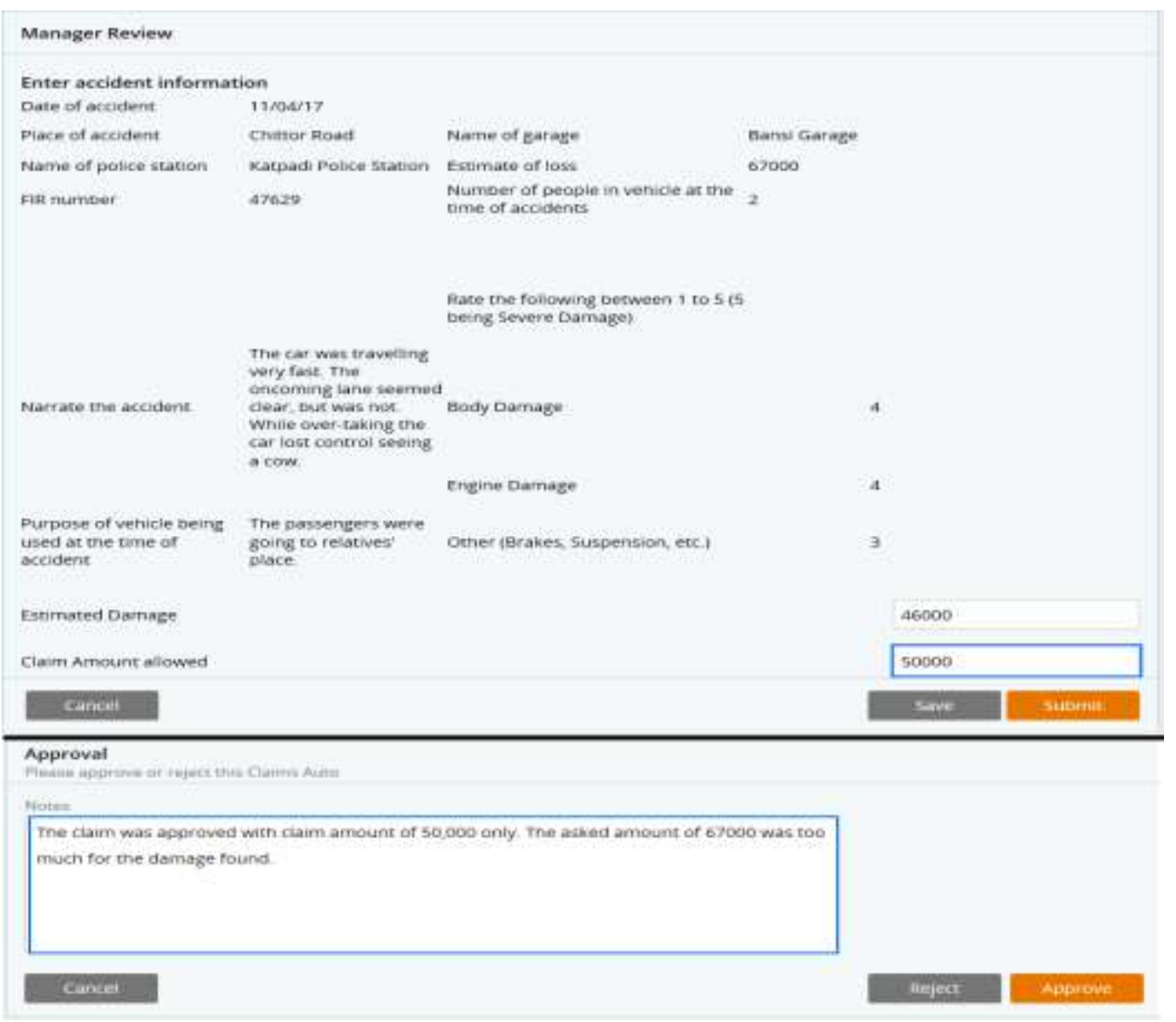

Figure 6. Screens Visible to the Manager's Work-Pool

Figure 6 includes two screenshots from the manager's portal. Manager work pool is a feature of Pega PRPC which allows multiple users who are at same access privilege level to access same instance and process it. In this case view the claim application of the client. The advantage of this is independency of work flow on one manager. The estimated damage field shows the manager the calculated value using the ratings. Now the manager can decide the amount of claim looking at all the details and estimated damage. The second screen shows the approval screen. In this screen, the manager can add comments about his approval.

Finally, the Figure 7 includes two screenshots from final confirmation screens. The client can view the approved claims amount by the manager. Also, the screenshot also displays the life cycle. Most of the steps are green indicating the processes finished and the last process is blue indicating current process and the steps is marked with blue arrow. The second screenshot of the Figure 7 shows the declaration by the client. 


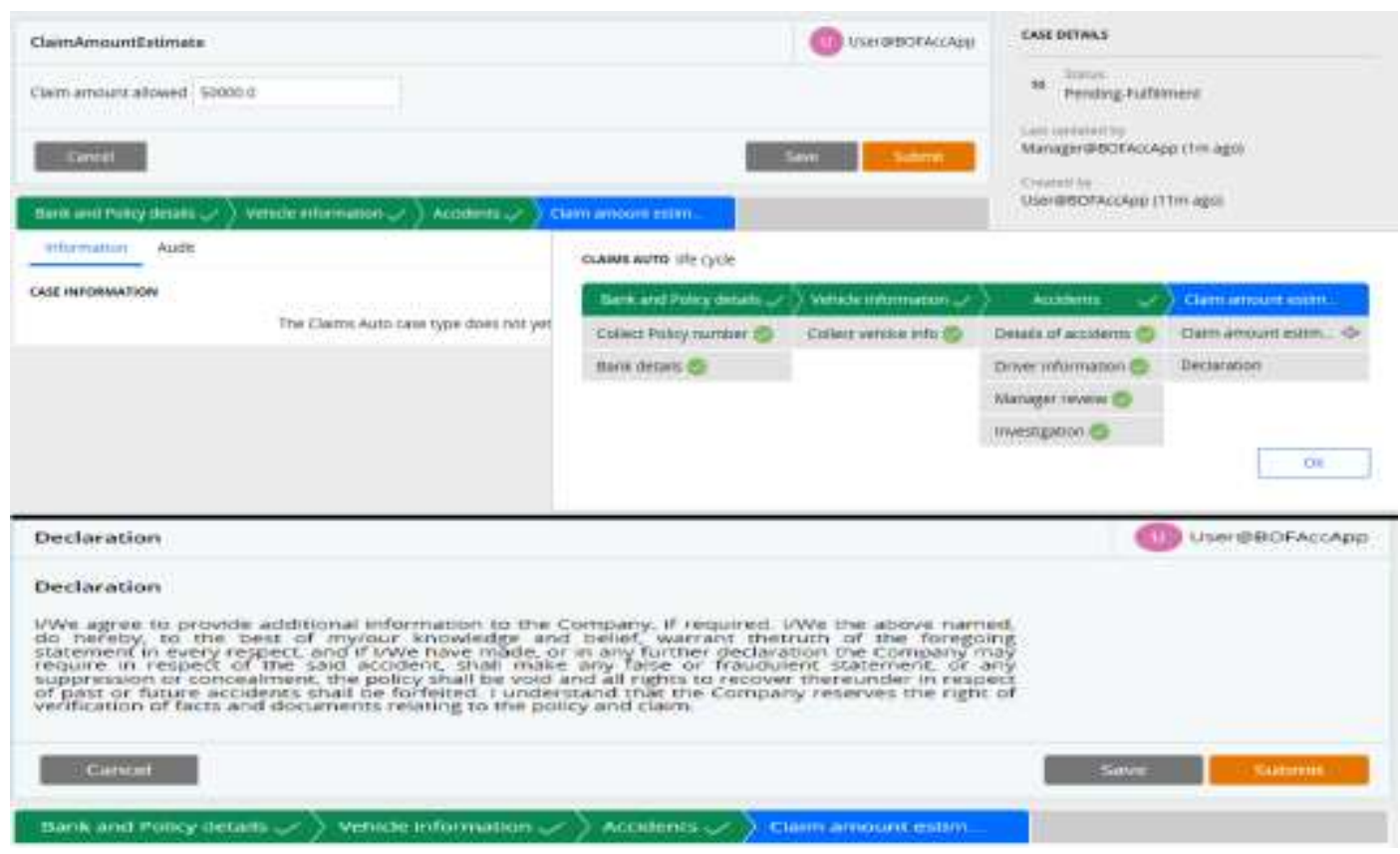

Figure 7. Final Screen and Declaration by the Client

\section{Results and Conclusion}

Given the rise in number of insurance policy holders a system with multiple insurance claims handling capacity is expected. This paper describes such an application. Pega PRPC is to be used to create the application. The experts in the industry take Pega as a very important player in business compared to other competitors. The application took much less time and effort to develop and maintain. This paper also describes and compares development of application using Pega and other similar tools. In the end the application was explained with screenshots from one of many modules developed.

\section{References}

[1] Mayers, D., \& Smith Jr, C. W., On the corporate demand for insurance. In Foundations of Insurance Economics, Springer Netherlands, (1982), pp. 190-205.

[2] J. D. Cassidy, L. J. Carroll, P. Côté, M. Lemstra, A. Berglund and A. Nygren, "Effect of eliminating compensation for pain and suffering on the outcome of insurance claims for whiplash injury", New England Journal of Medicine, vol. 342, no. 16, (2000), pp. 1179-1186.

[3] W. M. V. D. Aalst, A. H. T. Hofstede and M. Weske, "Business process management: A survey", In International conference on business process management, Springer Berlin Heidelberg, (2003), pp. 1-12.

[4] J. Becker, M. Rosemann and C. V. Uthmann, "Guidelines of business process modelling", In Business Process Management, Springer Berlin Heidelberg, (2000), pp. 30-49.

[5] A. W. Scheer and M. Nüttgens, "ARIS architecture and reference models for business process management”, In Business Process Management, Springer Berlin Heidelberg, (2000), pp. 376-389.

[6] "Business process management", in Wikipedia, Wikimedia Foundation, 2017. [Online]. Available: https://en.wikipedia.org/wiki/Business_process_management. Accessed: Feb. 11, 2017.

[7] "Business Process Management", in bpm.com, 2017. [Online]. Available: http://bpm.com/. Accessed: Feb. 12, 2017

[8] "Business rules engine", in Wikipedia, Wikimedia Foundation, 2016. [Online]. Available: https://en.wikipedia.org/wiki/Business_rules_engine. Accessed: Feb. 11, 2017

[9] S. Inaganti and G. K. Behara, "Service identification: BPM and SOA handshake", BPTrends, vol. 3, (2007), pp. 1-12.

[10] S. Marion, "Model driven collaborative business application development environment and collaborative applications developed therewith", U.S. Patent Application 10/273,359, filed October 18, 2002.

[11] J. V. Zeijts, "Rapid application development using the Tcl/Tk language", In Particle Accelerator Conference, 1995., Proceedings of the 1995 IEEE, vol. 4, (1995), pp. 2241-2243. 
[12] L. Zhang and W. Jiang, "Transforming business requirements into bpel: A mda-based approach to web application development”, In Semantic Computing and Systems, 2008. WSCS'08. IEEE International Workshop on, (2008), pp. 61-66.

[13] P. Ravesteyn and R. Batenburg, "Surveying the critical success factors of BPM-systems implementation", Business Process Management Journal, vol. 16, no. 3, pp. 492-507.

[14] H. A. Reijers, "Implementing BPM systems: the role of process orientation", Business Process Management Journal, vol. 12, no. 4, (2006), pp. 389-409.

[15] S. Brahe, "BPM on Top of SOA: Experiences from the Financial Industry. In International Conference on Business Process Management", Springer Berlin Heidelberg, (2007), pp. 96-111.

[16] D. Singh and P. Kumar, "Design of Integrated Business Intelligence System Framework for Insurance Business Processes”, International Journal of Applied Information Systems, vol. 3, no. 3, (2012), pp. 4248.

[17] D. Szalewska, P. Niedoszytko and K. G. Haponiuk, "The impact of professional status on the effects of and adherence to the outpatient followed by home-based telemonitored cardiac rehabilitation in patients referred by a social insurance institution", International journal of occupational medicine and environmental health, vol. 28, no. 4, (2014), pp. 761-770.

[18] M. Z. Muehlen and D. T. Y. Ho, "Risk management in the BPM lifecycle. In International Conference on Business Process Management”, Springer Berlin Heidelberg, (2005), pp. 454-466.

[19] G. Wegmann, "The balanced scorecard as a knowledge management tool: a French experience in a semipublic insurance company", (2007).

[20] S. Suriadi, M. T. Wynn, C. Ouyang, A. H. T. Hofstede and N. J. V. Dijk, "Understanding process behaviours in a large insurance company in Australia: A case study", In International Conference on Advanced Information Systems Engineering, Springer Berlin Heidelberg, (2013), pp. 449-464.

[21] M. Rosemann and J. C. Recker, "Context-aware process design: Exploring the extrinsic drivers for process flexibility", In The 18th International Conference on Advanced Information Systems Engineering. Proceedings of Workshops and Doctoral Consortium, Namur University Press, (2006), pp. 149-158.

[22] P. Beyda, A. Seth, I. Apsel and M. Gitter, "American International Group, Inc., Systems, Methods, and Computer Program Products for Processing Insurance Claims", U.S. Patent Application 13/310,528. 2011

[23] F. Leymann, D. Roller and M. T. Schmidt, "Web services and business process management", IBM systems Journal, vol. 41, no. 2, (2002), pp. 198-211.

[24] "Industry Overview", III, 2017. [Online]. Available: http://www.iii.org/fact-statistic/industry-overview. [Accessed: 12- Feb- 2017].

[25] System Architect Essentials (7.2). [Online]. Available: http://www.academy.pega.com

[26] PRPC: Fundamentals (V6.3). [Online]. Available: http://www.academy.pega.com

[27] L. Fischer, "iBPMS, 1st ed. Lighthouse Point", Fla.: Future strategies [u.a.], (2013).

[28] M. Weske, "Business process management", 1st ed. Heidelberg: Springer, (2012).

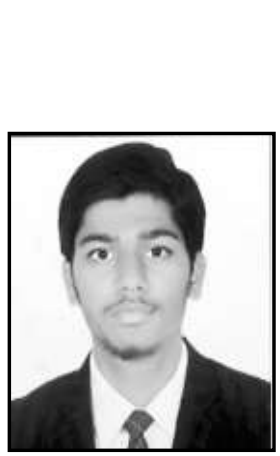

\section{Authors}

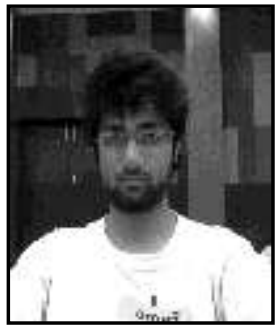

Nikhil Chaudhari, is with the school of Computer Engineering at VIT University, Vellore, India. His research interests lie in embedded systems, Soft Computing, Cryptography algorithms, and Image processing. He is currently executing many projects in the same.

Astitv Nagpal, is a Final Year Undergraduate Student associated with VIT University, Vellore doing his Bachelors in Computer Science \& Engineering. He is interested in Cloud Computing and Distributed Computing and has Interned with Microsoft on their Azure Platform. He also really enjoys Software Development and he got an opportunity to work on PEGA PRPC while interning with VirtusaPolaris in New Jersey, USA. Currently he is placed with VMware and will be joining them soon. 


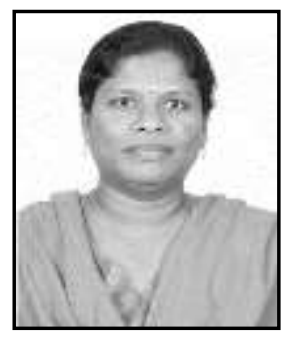

H. Santh, is working as an Associate Professor in the School of Computing Science and Engineering at VIT University, Vellore, Tamil Nadu, India. She received her PhD in Computer Science from VIT University. She has 12 years of experience in teaching and research. She has published many papers in international and national journals and conferences on network security, computer networks and wireless mobile networks. Her research interest includes wireless networks, mobile network security and big data. She is a life member of Computer Society of India. 
International Journal of $u-$ and e- Service, Science and Technology Vol.10, No.7 (2017) 